\title{
ANÁLISE PRELIMINAR DAS CARACTERÍSTICAS AMBIENTAIS EM ESPAÇO DE LAZER: PISTA DE CAMINHADA DA UFMT
}

\author{
Vanessa de Souza Luz \\ Mestranda do Programa de Pós-Graduação em Física Ambiental/ UFMT, Linha de Pesquisa: Análise Microclimática em \\ Sistemas Urbanos, E-mail: vanessaluz@live.com \\ Carolina de Rezende Maciel \\ Doutoranda em Física Ambiental/ UFMT, Linha de Pesquisa: Análise Microclimática em Sistemas Urbanos, E-mail: \\ carolmaciel_arq@yahoo.com.br \\ Osvaldo Borges Pinto Júnior \\ Professor da Universidade de Cuiabá/ UNIC, Professor do Programa de Pós-Graduação em Física Ambiental, \\ Linha de Pesquisa: Análise Microclimática em Sistemas Urbanos, E-mail: osvaldo.borges@gmail.com \\ Marta Cristina de Jesus Albuquerque Nogueira \\ Professora do Departamento de Arquitetura e Urbanismo/ FAET/ UFMT, Professora do Programa de Pós-Graduação \\ em Física Ambiental, Linha de Pesquisa: Análise Microclimática em Sistemas Urbanos, E-mail: mcjanp@gmail.com \\ José de Souza Nogueira \\ Professor do Departamento de Física/ IF/ UFMT e Coordenador do Programa de Pós-Graduação em Física \\ Ambiental, E-mail: nogueira@ufmt.br
}

$\underline{\text { http://dx.doi.org/10.5902/223611707709 }}$

\section{RESUMO}

A cidade de Cuiabá, capital de Mato Grosso, possui um rigor climático constante quase o ano todo. Atualmente, grande parte da população acredita que a única solução para a atenuação do desconforto térmico da cidade é a climatização dos ambientes fechados, enquanto o conforto ambiental externo fica em segundo plano, quase como inexistente, já que as áreas verdes são gradativamente suprimidas e o solo impermeabilizado "em prol do crescimento" da cidade. São poucas as áreas verdes voltadas para o lazer em nossa cidade. Nesse cenário, a pista de caminhada da Universidade Federal de Mato Grosso surge como uma demonstração de que os espaços construídos e naturais podem ser conciliados harmoniosamente em meio aos espaços densamente urbanizados. Nessa pista de caminhada encontramos pessoas de diferentes bairros de Cuiabá/ MT e estudantes da universidade, sendo os horários de maior fluxo de utilização da pista o início da manhã e o final da tarde, com maior frequência nos fins de semana. $O$ objetivo geral desta pesquisa é levantar as características do local quanto à ocupação do solo, vegetação e clima e, em seguida realizar análise sobre o impacto dessas características no conforto térmico dos usuários. Para a realização deste estudo foram coletados dados ao longo do percurso de maior utilização pelos usuários, onde foram coletados dados de temperatura, umidade do ar e temperaturas superficiais sendo os horários de coleta às $07 \mathrm{~h}$ e $17 \mathrm{~h}$. 0 trajeto completo tem aproximadamente dois quilômetros. Estes estudos vêm se desenvolvendo no período da primavera (final do ano de 2011 e início de 2012) e outono, sendo os dados coletados nos meses de novembro, dezembro e março. Os resultados obtidos com esta pesquisa nos permitirão analisar a influência da vegetação na amenização do clima local, bem como o conforto proporcionado aos usuários. 
Palavras-chave: Vegetação, clima urbano, conforto.

Titulo em INGLÊS

\section{ABSTRACT}

The city of Cuiabá, capital of Mato Grosso, has a rigorous climate almost all year round, and its urban structure resulting from uncontrolled and unplanned growth aggravates this situation. Nowadays, much of the population believes that the only solution to reducing thermal discomfort of the city is the air-conditioning indoors, while outdoor environmental comfort is in the background, almost nonexistent, since the green areas are gradually removed and the soil proofed "for growth" of the city. There are few green areas aimed at leisure in Cuiabá. In this scenario, the hiking trail from the Federal University of Mato Grosso appears as a demonstration that the built and natural spaces can be reconciled harmoniously amid the densely urbanized areas. In this walking track can be found people from different neighborhoods in Cuiabá / MT as well as university students, and the times of highest use are early in the morning (06h to 08h) and late afternoon (17h to $19 \mathrm{~h}$ ), more often on weekends.The objective of this research is the characterization of the site regarding land use, vegetation and climate, and then perform analysis on the impact of these characteristics on the thermal comfort of the users. For this study points were marked every 100 meters, totaling 22 points of data collection, the route of more use by users, where data were collected on temperature, humidity and surface temperatures. The schedule of collection was set to $07 \mathrm{~h}$ and $17 \mathrm{~h}$ (local time with the greatest number of people). The route begins at Avenida Fernando Correa da Costa to the football field at the Federal University of Mato Grosso returning to the starting point, completing a journey of about two kilometers. These studies see developing in the summer period (late 2011 and early 2012) and autumn, and the data collected during November, December and March. The results of this research will analyze the influence of vegetation on local climate mitigation as well as the comfort provided to users.

Keywords: Vegetation, urban climate, comfort.

\section{INTRODUÇÃO}

Atualmente as grandes cidades encontram-se num estágio de busca pelo desenvolvimento e crescimento, acompanhando o ritmo global. Essa busca, muitas vezes, causa o aumento desordenado e sem planejamento das cidades, onde a preocupação com áreas destinadas ao lazer e bem-estar da população fica em segundo plano, bem como espaços arborizados e permeáveis em meio ao ambiente urbano. O conforto nas áreas externas está perdendo seu espaço, uma vez que as pessoas preocupam-se em condicionar os espaços internos e as áreas vegetadas são suprimidas pela pavimentação decorrente do crescimento da cidade. Esse fato implica diretamente no conforto dos usuários do meio urbano, pois a temperatura aumenta gradativamente e se intensifica de acordo com o aumento da impermeabilização do solo.

Nas últimas décadas, o crescimento e a concentração das populações nos centros urbanos tem acelerado o processo de mudança da cobertura das superfícies do solo. Este crescimento tem contribuído para o fenômeno das ilhas de calor, exigindo dos pesquisadores mais dedicação ao estudo da interação de variáveis microclimáticas com os materiais e formas que compõe o ambiente urbano.

No Mato Grosso, o crescimento populacional foi nítido principalmente na década de 1970, quando, de acordo com SILVA (2000), a taxa de crescimento anual foi de $6,6 \%$, o que 
representa, em valores absolutos, que a população sextuplicou entre 1960 e 1991, quando passou de 325 mil para 2,027 milhões de habitantes.

Em Cuiabá, observa-se a falta de um planejamento urbano adequado que possa atender esta demanda demográfica por espaço e que tenha como objetivo o crescimento da cidade de maneira ordenada. Tão importante quanto um planejamento adequado, para o caso de Cuiabá especificamente, seria a adoção de um planejamento bioclimático, ou seja, que levasse em consideração o clima no qual a cidade está inserida.

O principal ganho de calor no meio urbano se dá pela radiação solar, que incide sobre as diversas superfícies encontradas na cidade. Essa forma de energia incidente é absorvida pelas áreas permeáveis e parte dela é devolvida ao ambiente. Com relação às áreas pavimentadas, o calor recebido é armazenado durante todo o dia, resultando no aumento da temperatura e supressão da umidade.

Além do solo permeável, estudos anteriores comprovam que a presença de árvores no ambiente possui muitas vantagens, uma vez que, além de propiciar sombra durante todo período de incidência solar, aperfeiçoa a umidade do ambiente, contribui para o controle da temperatura e bloqueia os raios incidentes diretos do sol.

Fica evidente, portanto, a necessidade de serem desenvolvidos trabalhos de cunho científico que abordem a dinâmica do espaço urbano, mais especificamente sobre clima urbano. Esta necessidade possui uma importância ainda maior para Cuiabá, cidade onde foi desenvolvida esta pesquisa, na qual são registradas temperaturas extremamente altas durante o ano inteiro.

\section{METODOLOGIA}

\subsection{Material}

Para desenvolvimento da pesquisa foi escolhido um trajeto em uma pista de caminhada localizada nas dependências da Universidade Federal de Mato Grosso, região leste de Cuiabá-MTBrasil, com extensão de aproximadamente de $2 \mathrm{~km}$, conforme Figura 1. A região apresenta clima Tropical Continental, sem influência marítima, onde já foi detectada a interferência do uso do solo urbano na ocorrência de ilhas de calor, baixa frequência e velocidade média dos ventos. Para o trajeto determinou-se 21 pontos distribuídos a cada $100 \mathrm{~m}$, posicionando-os de forma estratégica em locais de interesse de avaliação como: pontos expostos a radiação solar, bem como pontos em áreas que recebem cobertura arbórea. 


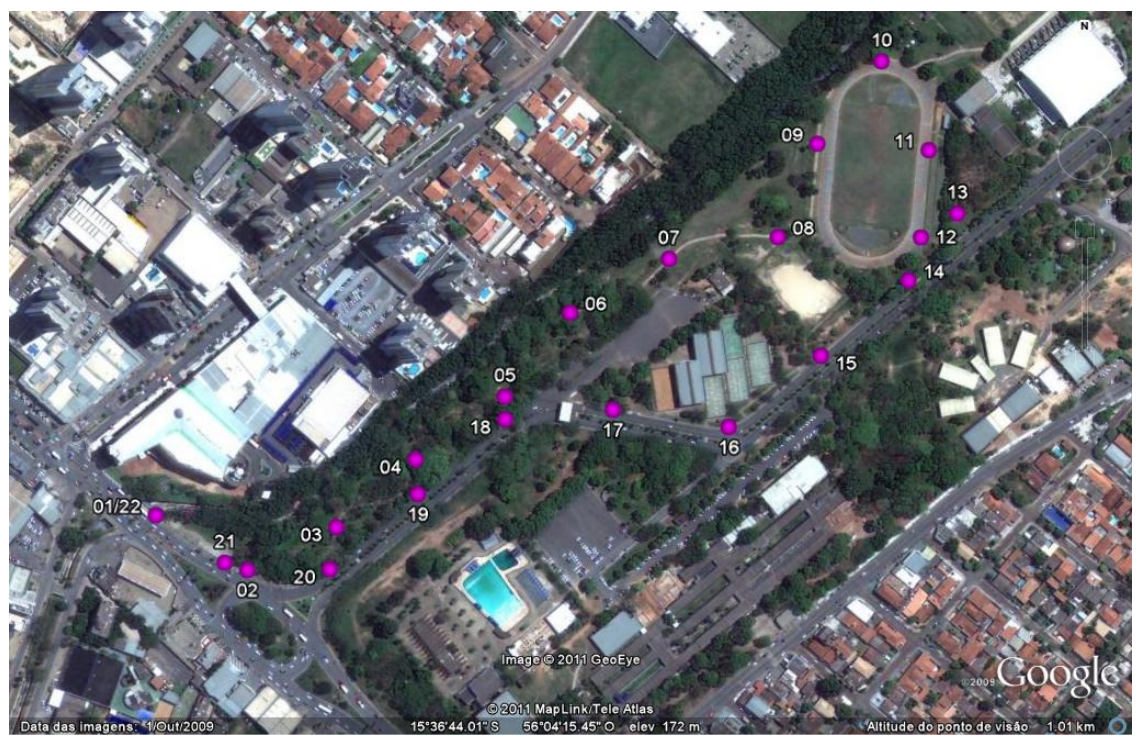

FIGURA 1 - Pontos de coleta das temperaturas

Fonte: Google Earth

\subsubsection{Coleta de dados in loco}

Os dados foram coletados por 04 dias consecutivos, no período matutino e vespertino (07h e 17h) em três estações do ano - primavera, verão e outono do ano de 2011 e 2012, por dois medidores, o termo higrômetro que mede a temperatura do ar e umidade relativa, e termômetro de temperatura superficial. Para proteção das intempéries utilizou-se um abrigo para proteção dos termômetros, confeccionados manualmente, Figura 2.

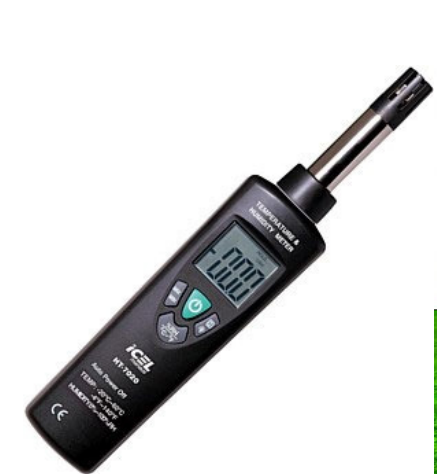

a)

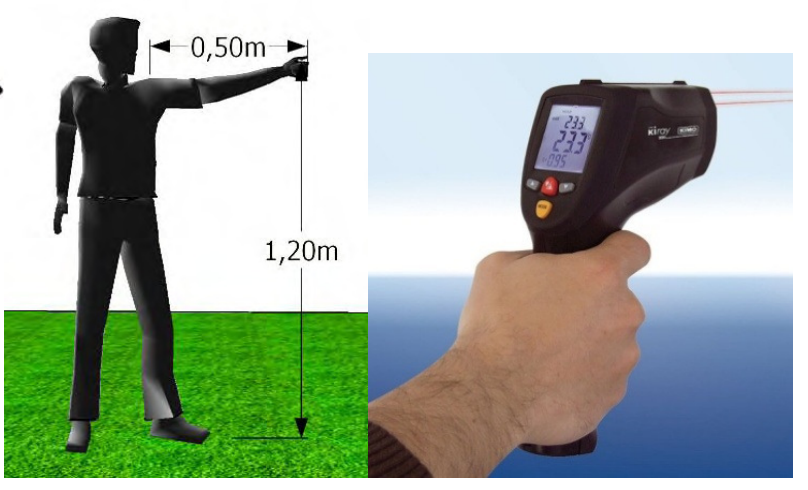

b)

c)

FIGURA 2 - (a) Termo-higrômetro digital; (b) Distanciamento utilizado para coleta das variáveis; (c) Termômetro a laser para temperatura superficial. 


\subsection{Métodos}

Essa pesquisa teve como método geral identificar a importância de espaços permeáveis, com presença de árvores e vegetação em geral para o conforto urbano, na qual se buscou fazer uma relação com a presença de ambientes como a Pista de Caminhada da Universidade Federal de Mato Grosso coexistindo na esfera urbana, e de que maneira isso afeta a porção do ambiente em questão.

\section{RESULTADOS E DISCUSSÕES}

Para análise dos resultados buscou-se o comparativo entre os três meses de coleta obtidos, definidos pelas três estações, identificando as diferenças apresentadas em relação às temperaturas que apresentam características distintas pela localização e pelos horários de coleta.

\subsection{Dados coletados na primavera}

Através dos dados coletados pôde-se observar que na estação da primavera os valores encontrados para as médias da temperatura do ar e temperatura superficial no período matutino foram menores que no período vespertino, apresentando uma diferença de aproximadamente $8,4^{\circ} \mathrm{C}$ para temperatura superficial, $4,7^{\circ} \mathrm{C}$ para temperatura do ar. Com relação à umidade no período vespertino houve uma redução apresentando uma diferença de 19,95 \%, Figura 3.
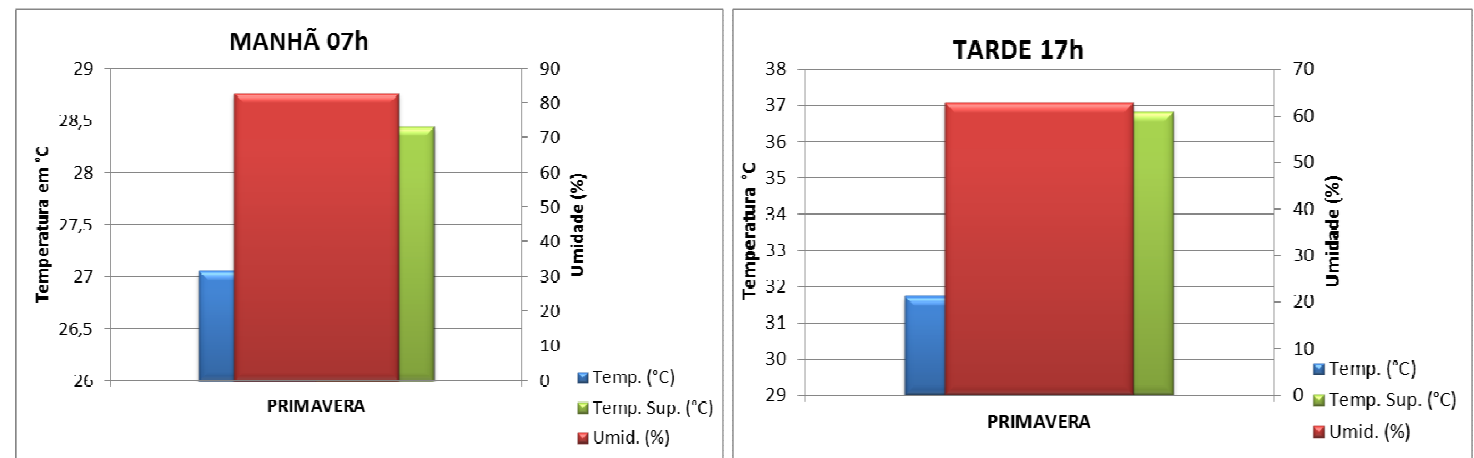

Figura 3 - Resultado comparativo das médias da estação da primavera - manhã e tarde

\subsection{Dados coletados no Verão}

Na estação Verão durante as medições no período matutino os valores encontrados para as médias da temperatura do ar e temperatura superficial foram menores que no período vespertino, apresentando uma diferença de aproximadamente $5,58^{\circ} \mathrm{C}$ para temperatura superficial e $6,7^{\circ} \mathrm{C}$ para temperatura do ar. Com relação à umidade no período vespertino houve uma redução apresentando uma diferença de 17,52\%, Figura 4. 

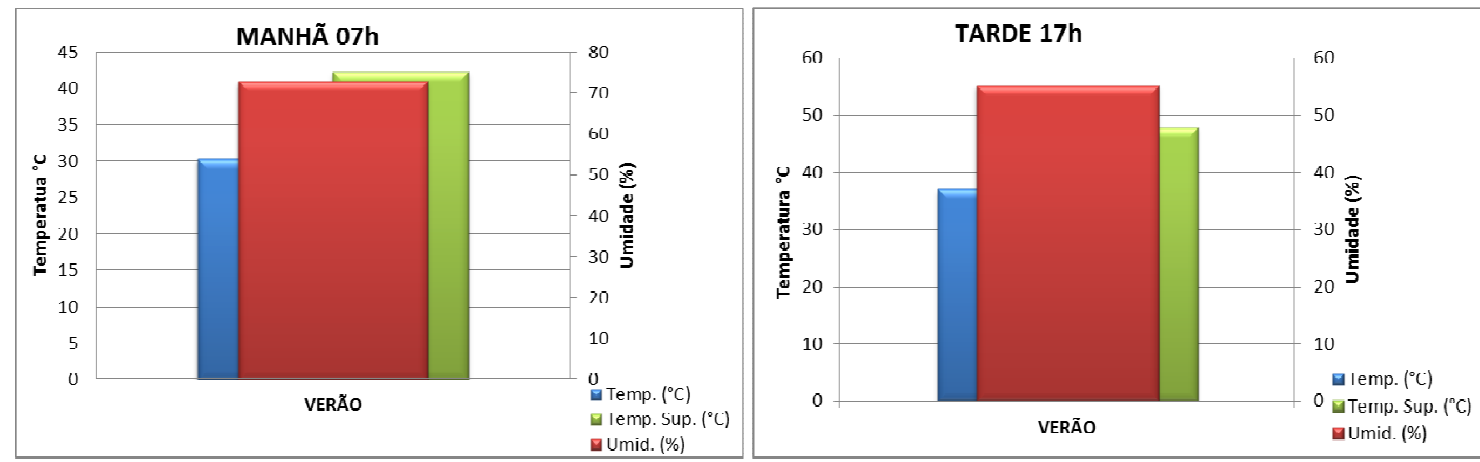

Figura 4 - Resultado comparativo da médias da estação Verão - manhã e tarde

Em relação às temperaturas superficiais obtidas, pode-se observar que as mesmas variam de acordo com os pontos de localização no trajeto e a média encontrada é um balanço entre os dois períodos.

\subsection{Dados coletados no Outono}

Através dos dados coletados pode-se observar que na estação Outono durante as medições no período matutino os valores encontrados para as médias da temperatura do ar e temperatura superficial foram menores que no período vespertino, apresentando uma diferença de aproximadamente $5,13^{\circ} \mathrm{C}$ para temperatura superficial e $2,94^{\circ} \mathrm{C}$ para temperatura do ar. Com relação à umidade no período vespertino houve uma redução apresentando uma diferença de 3,61 \%, menor do que apresentada nas estações anteriores, Figura 5.
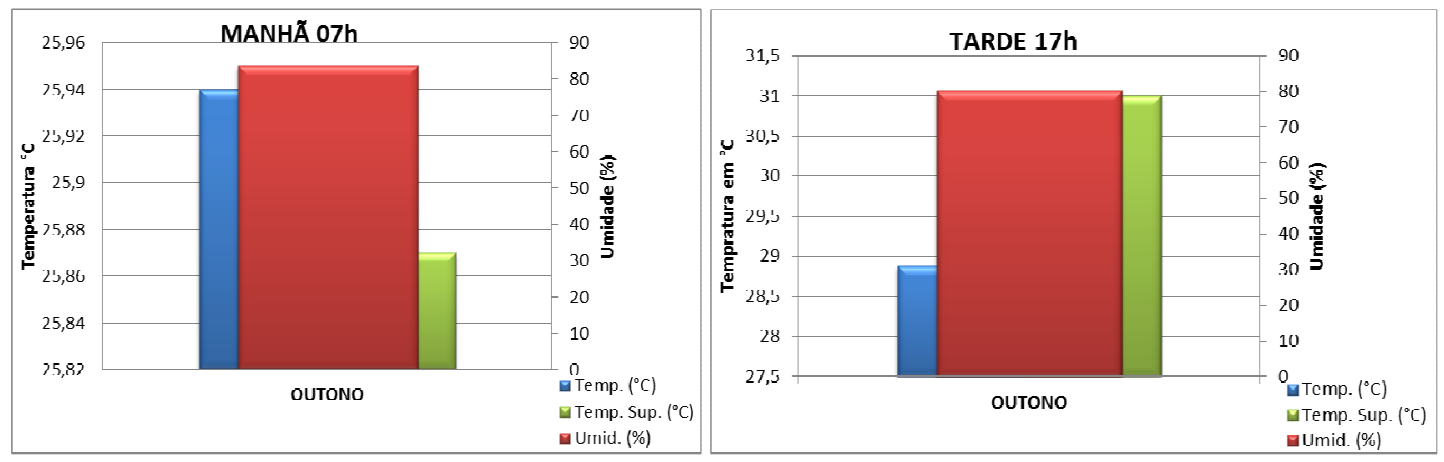

Figura 5 - Resultado comparativo das médias da estação Outono - manhã e tarde

\subsection{Análise geral das mínimas e máximas da temperatura do ar e umidade encontradas}

Para uma melhor análise dos dados coletados, buscou-se relacionar dentro de cada estação as temperaturas mínimas e máximas obtidas e seus respectivos pontos de coleta no trajeto, divididas em dois períodos (matutino e vespertino), conforme Tabelas 1 e 2 a seguir. 
Rev. Elet. em Gestão, Educação e Tecnologia Ambiental (e-ISSN: 2236-1170)

Tabela 1 - Registro da Temperatura do Ar no Período Matutino

\begin{tabular}{|c|c|c|c|c|c|}
\hline \multicolumn{7}{|c|}{ Temperatura do Ar ( (C) } \\
\hline Mês & Estação & Mínima & Ponto & Máxima & Ponto \\
\hline \multicolumn{7}{|c|}{ Período Matutino } \\
\hline Novembro & Primavera & 24,0 & 16 ao 20 & 30,5 & 20 \\
\hline Dezembro & Verão & 28,5 & 5 & 33,5 & 20 \\
\hline Março & Outono & 23,6 & 5 & 29,0 & 2 \\
\hline
\end{tabular}

Tabela 2 - Registro da Temperatura do Ar no Período Vespertino

\begin{tabular}{|c|c|c|c|c|c|}
\hline \multicolumn{7}{|c|}{ Temperatura do Ar ( C) } \\
\hline Mês & Estação & Mínima & Ponto & Máxima & Ponto \\
\hline \multicolumn{7}{|c|}{ Período Vespertino } \\
\hline Novembro & Primavera & 29,9 & 10 & 34,5 & 22 \\
\hline Dezembro & Verão & 36,1 & 22 & 40,2 & 17 \\
\hline Março & Outono & 25,3 & 12 & 33,1 & 15 \\
\hline
\end{tabular}

Observando o resumo de valores apresentados nas Tabelas 1 e 2 acima, pode-se notar um considerável aumento da temperatura do ar no período vespertino, enquanto no período matutino, esses valores são relativamente menores. Nas medições realizadas no período da manhã, a menor temperatura foi registrada na estação outono - mês de Março - no ponto 05 do transecto, apresentando valor de $23,60 \mathrm{C}$; enquanto a máxima temperatura registrada na mesma estação e mesmo período foi de 29 으, no ponto 02 .

Uma justificativa para essa diferença se dá pela localização dos pontos de coleta de dados, uma vez que o ponto 05 estava localizado entre árvores e solo permeável e o ponto 02 se localizava sob a calçada, possuindo como entorno a Avenida Fernando Correa da Costa - área pavimentada - e locais sem nenhuma barreira para os raios diretos do sol.

Da mesma maneira buscou-se relacionar dentro de cada estação as umidades mínimas e máximas obtidas e seus respectivos pontos de coleta no trajeto, divididas em dois períodos (matutino e vespertino), conforme Tabelas 3 e 4 a seguir.

Tabela 3 - Registro da Temperatura do Ar no Período Matutino

\begin{tabular}{|c|c|c|c|c|c|}
\hline \multicolumn{7}{|c|}{ Umidade do Ar (\%) } \\
\hline Mês & Estação & Mínima & Ponto & Máxima & Ponto \\
\hline \multicolumn{7}{|c|}{ Período Matutino } \\
\hline Novembro & Primavera & 71,6 & 22 & 91,5 & 13 \\
\hline Dezembro & Verão & 67,8 & 2 & 81,2 & 5 \\
\hline Março & Outono & 70,6 & 9 & 95,1 & 10 \\
\hline
\end{tabular}


Rev. Elet. em Gestão, Educação e Tecnologia Ambiental (e-ISSN: 2236-1170)

Tabela 4 - Registro da Temperatura do Ar no Período Vespertino

\begin{tabular}{|c|c|c|c|c|c|}
\hline \multicolumn{7}{|c|}{ Umidade do Ar (\%) } \\
\hline Mês & Estação & Mínima & Ponto & Máxima & Ponto \\
\hline \multicolumn{7}{|c|}{ Período Vespertino } \\
\hline Novembro & Primavera & 55,5 & 22 & 70,9 & 14 \\
\hline Dezembro & Verão & 48,4 & 18 & 59,2 & 5 \\
\hline Março & Outono & 62,9 & 2 & 90,0 & 11,13 e 14 \\
\hline
\end{tabular}

Com relação à umidade do ar, os números obtidos no período da manhã são mais altos que os do período da tarde. O ponto que apresentou menor valor de umidade do ar foi o de número 20 , com 48,4\%, registrado na estação Verão, no mês de Dezembro, na medição do período vespertino; enquanto a máxima umidade registrada na mesma estação e mesmo período foi de $59,2 \%$, no ponto 07 .

A umidade do ar varia de acordo com as condições do tempo no horário e local da realização da coleta de dados, diretamente relacionada com tempo chuvoso ou seco, juntamente com a presença ou não de sol; além do entorno e da localização dos pontos do transecto analisados. Com base nessas informações, observou-se que o ponto de maior valor foi o de número 11 , com 95,1\%, registrado na estação Outono, no mês de Março, na medição do período matutino, época do ano em que a ocorrência de precipitações é muito comum, deixando o ambiente relativamente mais úmido.

\section{CONCLUSÕES}

Este estudo buscou analisar as relações entre ambiente pavimentado e não pavimentado, utilizando das variáveis microclimáticas temperaturas e umidade, bem como temperatura superficial para tirar conclusões sobre a ocupação do solo, vegetação e conforto higrotérmico dos usuários da área de estudo analisada.

Com base nos resultados apresentados observou-se uma tendência aos pontos na área verde ou com proximidade a esta de apresentarem valores de temperaturas mais baixos.

A influência da vegetação sobre os microclimas, representadas nesta pesquisa pela extensa área verde da UFMT, corrobora afirmações de Mascaró (1996) e Santamouris (2001), de que as áreas verdes das cidades atuam sobre os elementos climáticos, contribuindo com o controle da radiação solar, temperatura do ar, ação dos ventos e chuva, além de amenizar a poluição em microclimas urbanos.

\section{AGRADECIMENTO}

À ELETROBRAS pelo apoio na pesquisa através das aquisições dos equipamentos.

\section{REFERÊNCIAS BIBLIOGRÁFICAS}

LOMBARDO, M. A. Ilha de Calor nas Metrópoles: O Exemplo de São Paulo. São Paulo: Hucitec, 1985. 244p.

MACIEL, C. R.; NOGUEIRA, M. C. J. A.; NOGUEIRA, J. S. Cobertura do solo e sua influência na temperatura de microclimas urbanos na cidade de Cuiabá-MT. 39 ed. Uberlandia: Universidade Federal de Uberlândia/ UFU/ On-Line, Set/2011. p. 40-57, v. 12. (Caminhos de Geografia). 
MASCARÓ, L. Ambiência Urbana. Porto Alegre: Sagra-D. C. Luzzato, 1996.

MONTEIRO, C. A. F.; MENDONÇA, F. (Org.). Clima Urbano. São Paulo: Contexto. 2003.

MUSIS, C. R De; NOGUEIRA, M. C. J. A. Estudos em conforto ambiental - Contribuições ao estudo de conforto ambiental e sistemas urbanos na grande Cuiabá-MT. 2. ed. Cuiabá/MT: Estúdio 11, 2010. 160p, v. 1. (Coletânea).

ROMERO, M. A. Arquitetura Bioclimática do Espaço Público. Brasília: Editora Universidade de Brasília, 2001.

ROMERO, M. A. B. Princípios bioclimáticos para o desenho urbano. 2. ed. São Paulo: Projeto, 2000. 128p.

SANTAMOURIS, M. (Ed). Energy and Climate in the urban built environment. James \& James Science Publishers, London, 2001, 402p.

Identificação dos Autores:

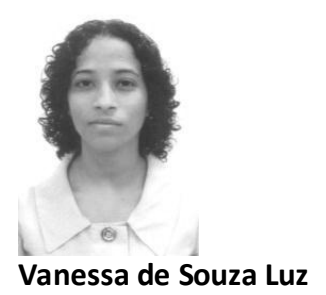

Graduação em Arquitetura e Urbanismo pela Universidade Federal de Mato Grosso/ UFMT

Mestranda pelo Programa de Pós Graduação em Física Ambiental/ PPGFA/ UFMT, Linha de Pesquisa: Análise Microclimática em Sistemas Urbanos, E-mail: vanessaluz@live.com

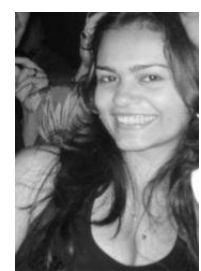

Carolina de Rezende Maciel

Graduação em Arquitetura e Urbanismo pela Universidade Federal de Mato Grosso/ UFMT;

Doutoranda pelo Programa de Pós Graduação em Física Ambiental/ PPGFA/ UFMT, Linha de Pesquisa: Análise Microclimática em Sistemas Urbanos, E-mail: carolmaciel_arq@yahoo.com.br 


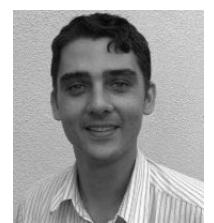

\section{Osvaldo Borges Pinto Júnior}

Graduação em Ciências Biológicas pela Universidade Estadual de Mato Grosso/ UNEMAT;

Professor Efetivo da Universidade de Cuiabá/ UNIC;

Professor do Programa de Pós Graduação em Física Ambiental/ PPGFA/ UFMT, Linha de Pesquisa: Análise Microclimática em Sistemas Urbanos, E-mail: osvaldo.borges@gmail.com

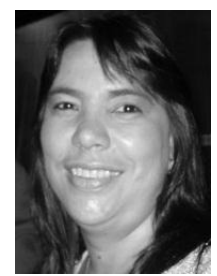

Marta Cristina de Jesus Albuquerque Nogueira

Graduação em Engenharia Civil pela Universidade Federal de Mato Grosso/ UFMT;

Professor Efetiva do Departamento de Arquitetura e Urbanismo/ UFMT;

Professora do Programa de Pós Graduação em Física Ambiental/ PPGFA/ UFMT, Linha de Pesquisa: Análise

Microclimáticas em Sistemas Urbanos, E-mail: mcjanp@gmail.com

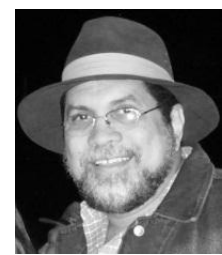

José de Souza Nogueira

Graduação em Licenciatura Plena em Física pela Universidade Federal de Mato Grosso/ UFMT;

Professor Efetivo do Instituto de Física/ UFMT;

Professor do Programa de Pós-Graduação em Física Ambiental e Coordenador do Programa de Pós-Graduação em Física Ambiental em nível de Mestrado e Doutorado, E-mail: nogueira@ufmt.br 